\title{
Clinical Features and Outcomes of Patients in Neonatal Intensive Care Requiring Laryngologic Consultation for Airway Disorders
}

\author{
Jin Youp Kim, Doh Young Lee, Hyun Chang, \\ Dong Wook Kim, Myung-Whun Sung, and Jeong Hun Hah \\ Department of Otorhinolaryngology-Head and Neck Surgery, Seoul National University College of Medicine, Seoul, Korea
}

기도 질환으로 의뢰된 신생아 중환자실 환자들의 임상 양상과 치료 결과

김진엽 · 이도영 · 장 현 · 김동욱 · 성명훈 · 하정훈

서울대학교 의과대학 이비인후과학교실

Received September 6, 2016

Revised October 19, 2016

Accepted October 19, 2016

Address for correspondence

Jeong Hun Hah, MD, PhD

Department of Otorhinolaryngology-

Head and Neck Surgery,

Seoul National University

College of Medicine, 101 Daehak-ro,

Jongno-gu, Seoul 03080, Korea

Tel $+82-2-2072-0215$

Fax $+82-2-745-2387$

E-mail jhunhah@snu.ac.kr
Background and Objectives Airway problems frequently occur in neonatal patients requiring intensive care due to high prevalence of intubation history and congenital conditions that are linked to craniofacial or upper aerodigestive tract anomalies. However, many investigations on airway disorders have examined large populations of hospitalized children without focusing on those treated in the intensive care unit (ICU). Here we present the clinical features and outcomes in infants hospitalized with airway-related problems at the neonatal ICU.

Subjects and Method A total 69 patients were studied from May 2005 to December 2012, with each examined by an otolaryngologist while in neonatal ICU (NICU) for possible airway problems. Descriptive analysis was used in evaluating illnesses suffered and subsequent upper airway treatments. Factors associated with tracheostomy were identified by multivariate analysis. Results The median age of infants was 30 days (range, 1-237 days), with a male-to-female ratio of 1.38 . The median gestational age was $35^{+3}$ weeks, and the mean birth weight was $2.35 \pm 0.89 \mathrm{~kg}$. Overall, 40 patients had histories of intubation (median duration, 36 days; range, 1-204 days). The most common diagnosis in the upper airway exam was laryngomalacia $(n=12)$, followed by subglottic stenosis $(n=10)$ and micrognathia $(n=8)$. Tracheostomy was performed in 38 patients $(55.1 \%)$. In multivariate analysis, intubation history was identified as the only variable demonstrating a significant independent association with tracheostomy $(p=0.006)$.

Conclusion Upper airway problems in NICU patients are due to a variety of disorders. Precise diagnosis and treatment is achievable through bedside and intraoperative assessments. Patients with a history of intubation are at increased risk of tracheostomy. Korean J Otorhinolaryngol-Head Neck Surg 2017;60(1):24-9

Key Words Neonatal intensive care unit · Subglottic stenosis · Tracheostomy Upper airway obstruction.

\section{Introduction}

Pediatric airway problems result from a variety of congenital and acquired conditions, all requiring careful assessment and individually tailored treatments. Congenital conditions that inevitably involve airway compromise are primarily linked to craniofacial or some upper aerodigestive tract anomalies, whereas most acquired conditions are attributable to subglottic stenosis after tracheal intubation. ${ }^{1)}$

Advances in treatments of critically ill infants have increased 
survival rates in medically complex infants with extremely or very low birth weights. However, improved survival may entail prolonged mechanical ventilation and often tracheostomy. ${ }^{2)}$ Tracheostomy (as opposed to translaryngeal intubation) is generally thought advantageous, based on a substantial body of accruing evidence in adults that intensive care unit (ICU) and hospital stays are reduced, and quality of life is improved. ${ }^{3)}$ However, much less is known about current practice and patient outcomes in neonatal ICUs (NICUs). With few exceptions, studies confirm that early tracheostomy reduces the incidence of subglottic and tracheal stenosis in children who are intubated for long periods of time. ${ }^{4)}$ On the other hand, tracheostomy in children has increased paradoxically, commensurate with advances in intensive care management of pediatric patients. Indeed, a recent review of early (2000-2005) and late (2006-2011) patient data shows a decreasing number of tracheostomies for prolonged intubation but an increasing number for obstructive upper airway problems. ${ }^{5)}$ Until recently, many investigations have examined large populations of hospitalized children, without focusing on those treated in ICUs. ${ }^{6,7)}$ Subsequently, the benefits or risks of tracheostomy in this setting have scarcely been addressed, and no national or international guidelines have emerged for tracheostomy use, especially in NICU patient subsets.

NICU staff pediatricians typically are not authorities on craniofacial or pediatric airway anomalies, so dangerous airway stenosis (from prolonged intubation) is sometimes overlooked. Such disorders require the diagnostic and therapeutic expertise of a consulting otolaryngologist, who can only be summoned by primary physicians in charge. In this study, clinical features and outcomes of NICU patient referrals for potential airway problems were analyzed retrospectively, in conjunction with various factors implicated in tracheostomy procedures.

\section{Subjects and Method}

A retrospective review was conducted, examining the medical records of 1548 patients admitted to the NICU between May, 2005 and December, 2012. Although 73 of these patients were evaluated by an otolaryngologist for suspected airway disorders (interval prevalence: $4.71 \%$ ), a total of 69 patients $(91.8 \%)$ seen by the same airway specialist (JHH) in the Department of Otorhinolaryngology were selected for study. Patient parameters under investigation included age, gender, birth weight, body weight, gestational history, underlying disorder, intubation history, reason for consultation, diagnosis, and treatment. This study was approved by the Institutional Review Board of Seoul National University Hospital.

Upon referral to this specialist, the oral cavity was examined visually, with good illumination; and upper airways (nasal cavity, nasopharynx, oropharynx, hypopharynx, and larynx) were inspected via transnasal or transoral passage of a 2.7-mm fiberoptic flexible laryngoscope (Olympus Medical Systems, Tokyo, Japan). To further evaluate any detected laryngotracheal pathology in the mentioned exams, suspension laryngoscopy was performed under general anesthesia in an operating room. After inserting a pediatric laryngoscope, visually guided (Stryker HD system; Stryker Corp., Kalamazoo, MI, USA) 2.9- or 4-mm rigid endoscopic examination (Karl Storz, Tuttlingen, Germany) took place.

Patients were referred to the Department of Otorhinolaryngology for the following reasons: 1) prolonged ventilation (conversion from orotracheal intubation to tracheostomy), 2) upper airway evaluation (with or without definitive upper airway symptoms), and 3) lower airway assessment. In accord with stated reasons for consultations, diagnostic and therapeutic features were analyzed, as were outcomes of patients undergoing tracheostomy. Clinical data of patients who did or did not undergo tracheostomy after upper airway evaluations were subjected to multivariate analysis.

Statistical analysis relied on standard software (SPSS v20.0 for Windows; SPSS Inc., Chicago, IL, USA). Chi-squared test, Fischer's exact test, Student t-test, Non-parametric MannWhitney $U$ test and binary logistic regression analysis were performed to evaluate clinical characteristics of patients who underwent tracheostomy. A $p$ value $<0.05$ was considered statistically significant.

\section{Results}

Clinical characteristics of the 69 patients studied are summarized in Table 1. Median age was 30 days (range, 1-237 days), and male-to-female ratio was 1.38. Median gestational age was $35^{+3}$ weeks (range, $28^{+3}-42^{+3}$ ) weeks. Mean birth weight and mean body weight were $2.35 \pm 0.89 \mathrm{~kg}$ and $2.55 \pm$ $0.97 \mathrm{~kg}$, respectively. Twenty-two patients had multiple underlying disorders. Singly occurring underlying disorders were distributed as follows: craniofacial anomaly (5), pulmonary disease (12), cardiovascular disease (2), and neurologic disease (12), tracheoesophageal fistula (4) and others (5) (Table 1). A history of intubation (median duration, 36 days; range, 1-204 
days) was elicited in 40 patients $(58.0 \%)$.

Reasons for consultation were as follows: tracheostomy (16); upper airway evaluation (49); and lower airway assess-

Table 1. Characteristics of 69 patients who were consulted for suspicious airway problem

\begin{tabular}{|c|c|}
\hline Age (range) & 30 days $(1-237)$ \\
\hline $\operatorname{Sex}(M: F)$ & $1.38: 1$ \\
\hline Median gestational age (range) & $35^{+3}$ weeks $\left(28^{+3}-42^{+3}\right)$ \\
\hline Birth weight $(\mathrm{kg} \pm \mathrm{SD})$ & $2.35 \pm 0.89$ \\
\hline Body weight (kg $\pm S D)$ & $2.55 \pm 0.97$ \\
\hline \multicolumn{2}{|l|}{ Underlying disorders (\%) } \\
\hline Craniofacial anomaly & $5(7.2)$ \\
\hline Pulmonary disease & $12(17.4)$ \\
\hline Cardiovascular disease & $2(2.9)$ \\
\hline Neurologic disease & $12(17.4)$ \\
\hline Tracheoesophageal fistula & $4(5.8)$ \\
\hline Others & $5(7.2)$ \\
\hline Multiple & $22(31.9)$ \\
\hline None & $7(10.1)$ \\
\hline \multicolumn{2}{|l|}{ Intubation history (\%) } \\
\hline Yes & $40(58.0)$ \\
\hline No & $29(42.0)$ \\
\hline Duration of intubation (range) & 36 days $(1-204)$ \\
\hline \multicolumn{2}{|l|}{ Reason for consultation } \\
\hline $\begin{array}{l}\text { For tracheostomy (due to long-term } \\
\text { intubation) }\end{array}$ & 16 \\
\hline $\begin{array}{l}\text { Upper airway evaluation (with } \\
\text { definite symptom) }\end{array}$ & 40 \\
\hline $\begin{array}{l}\text { Upper airway evaluation (without } \\
\text { definite symptom) }\end{array}$ & 9 \\
\hline Lower airway evaluation & 4 \\
\hline Tracheostomy & $38(55.1 \%)$ \\
\hline
\end{tabular}

ment (4), by rigid bronchoscopy (Fig. 1). Of the 49 referrals for upper airway distress, definitive obstructive symptoms of upper airways, such as stridor, chest retractions, and dyspnea on feeding were confirmed in 40; whereas symptoms such as voice change or poor crying were listed for the other nine. Nineteen of the 40 clearly symptomatic patients were able to breathe on their own, 13 were dire without intubation (intubated states), and eight required continuous positive airway pressure. Based on the symptoms documented, diagnoses were as follows: laryngomalacia (12), subglottic stenosis (10), micrognathia (8), posterior glottic stenosis (3), tracheomalacia (3), choanal atresia (3), and head and neck masses (2) (Fig. 2).

Suspension laryngoscopy was ultimately performed in 24 moderate-to-severely symptomatic patients (Fig. 3). The 10 patients with subglottic stenosis were managed endoscopically (i.e., bougie dilatation), in conjunction with tracheostomy, although the latter proved unnecessary in one instance of vallecular cyst. In six of 13 patients under observation preliminarily (no endoscopic management), tracheostomy was eventually required. However, further work-up was halted in 14 patients assessed as follows: no airway disease (7), mild laryngomalacia (5), micrognathia (1), and tracheomalacia (1). Symptoms abated in 10 of these patients, two deaths occurred from other underlying disease, and two patients were not followed.

Overall, tracheostomy was performed in 38 patients $(55.1 \%)$, including 22 instances of airway obstruction (20 cases with upper airway problem and 2 cases with tracheomalacia) and
Fig. 1. Consultation and treatment algorithm in patient population $(n=69)$. NICU: neonatal intensive care unit.

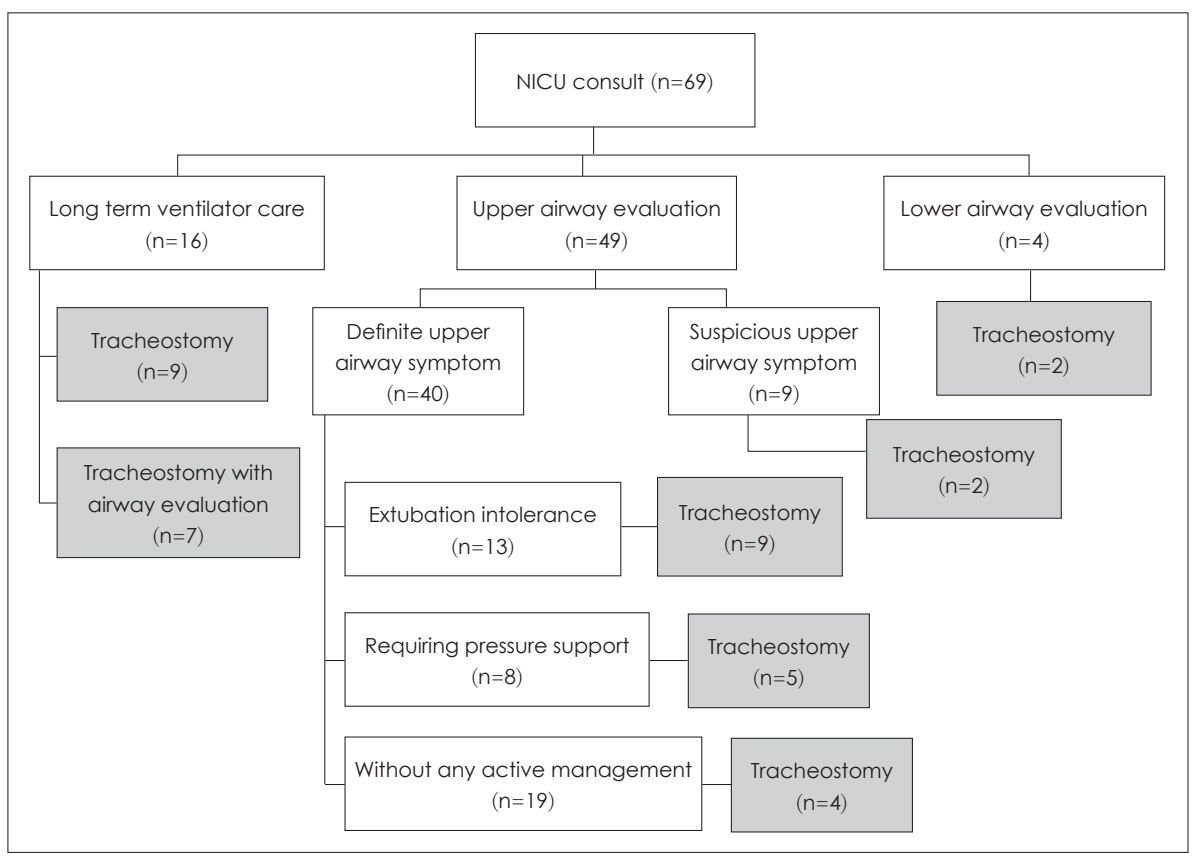


16 patients intubated long-term. Median gestational age of patients with airway obstruction was $36^{+5}$ weeks (range, $25^{+5}-$ $41^{+3}$ weeks); median patient age was 31 days (0-126 days); and median duration of follow-up was 40.0 months (range, 4 days -99 months). The decannulation rate was $64.3 \%$. Four patients eventually required open surgical procedures, such as laryngotracheal reconstruction with grafting of rib cartilage. In addition, were five patients retained tracheostomies, six were lost to follow-up, and two died of underlying disorders.

Univariate analysis of patients referred for upper airway assessment, whether or not tracheostomies were done, showed significant differences in birth weight ( $p=0.024)$, body weight $(p=0.008)$ and in histories of intubation $(p<0.001)$ (Table 2$)$.

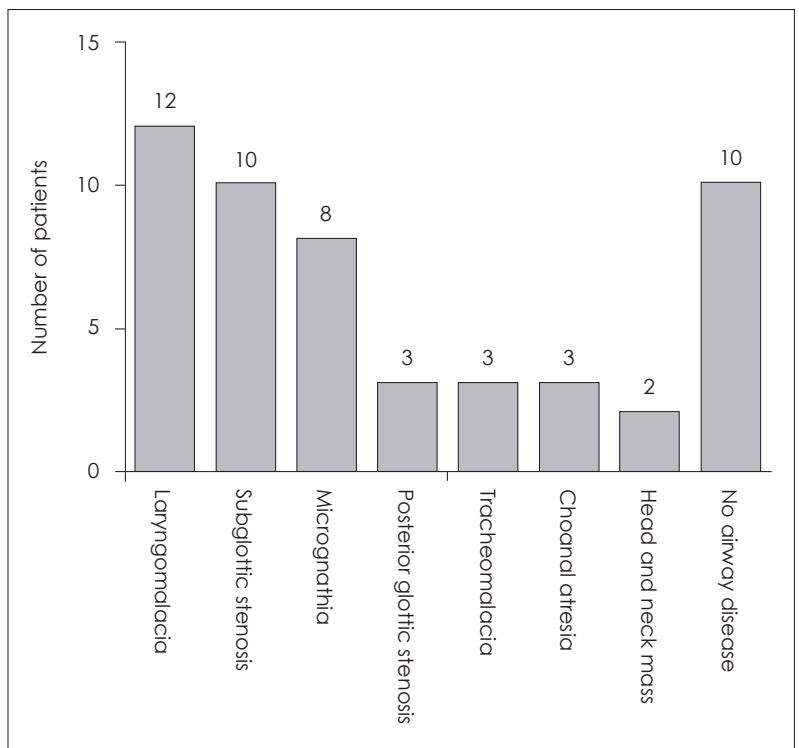

Fig. 2. Diagnoses in patients with definitive upper airway symptoms $(n=40)$. The numbers are not mutually exclusive.
Age and parameters which were statistically significant in the univariate analysis were involved in the multivariate analysis. Body weight was not included in the multivariate analysis due to close correlation between birth weight and body weight. In multivariate analysis, history of intubation was identified as the only significant independent correlate of tracheostomy (odds ratio $=12.50,95 \%$ confidence interval: $3.145-50.00$; $p=0.002$ ).

\section{Discussion}

Described herein are procedures used in specialty consultation to evaluate and treat NICU patients for airway problems. As our data indicates, such problems are not uncommon in a NICU setting (interval prevalence: $4.71 \%$ ). Although the patients studied suffered an array of conditions, these disorders were easily discernible, either at bedside assessment or through further suspension laryngoscopic investigation under general anesthesia. The importance of physical examination and fiberoptic laryngoscopy for the initial work-up cannot be overstated. In fact, the need for suspension laryngoscopy under general anesthesia is often averted by bedside identification of craniofacial anomalies and structural defects of oral/nasal cavities, pharynx, and larynx (above vocal cord). Our data indicate that as a consequence of initial bedside workups, suspension laryngoscopy was unnecessary in $35.0 \%$ of patients with definitive upper airway obstructive symptoms (Fig. 3).

Ultimately, about half of subjects (20/49, 40.8\%) referred to us for upper airway evaluations required tracheostomies. Compared with adult patients, neonates and infants are effec-

Fig. 3. Treatment flow chart in patients with definitive upper airway symptoms $(n=40)$.

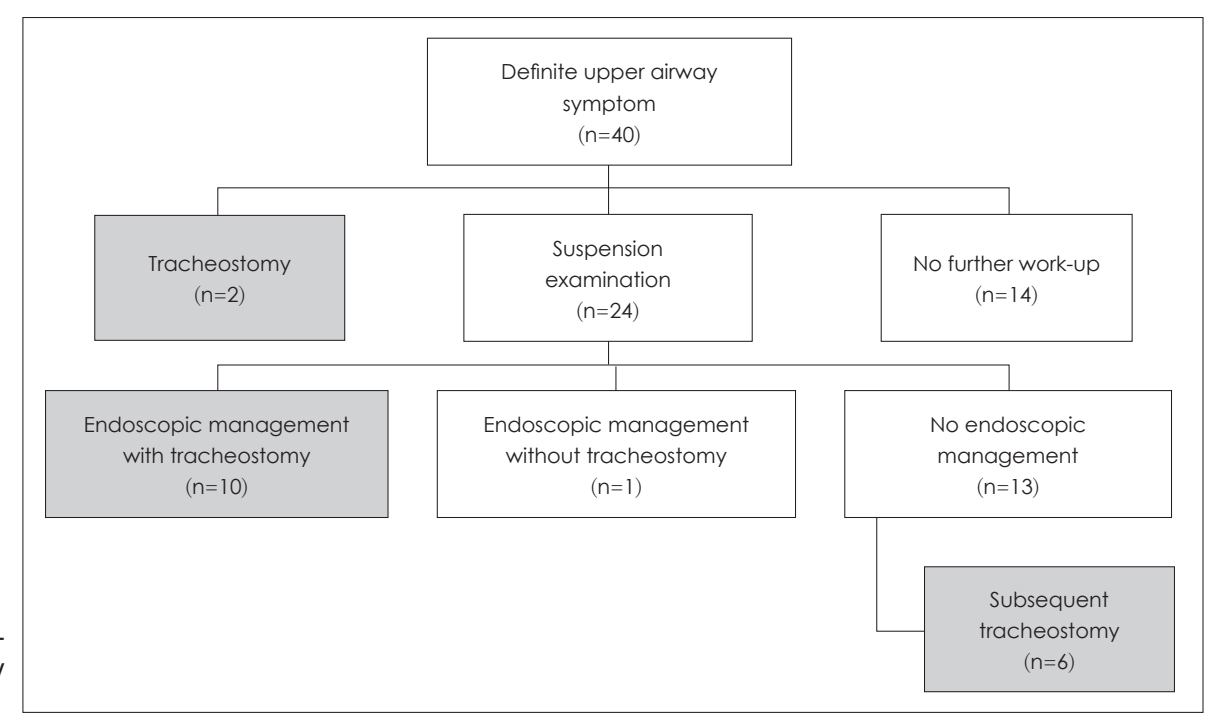


Table 2. Comparison of the patient groups according to the performance of tracheostomy after upper airway evaluation $(n=49)$

\begin{tabular}{|c|c|c|c|c|c|c|c|}
\hline & \multirow{2}{*}{$\begin{array}{c}\text { Tracheostomy }(+) \\
\qquad(n=20)\end{array}$} & \multirow{2}{*}{$\begin{array}{c}\text { Tracheostomy }(-) \\
\qquad(n=29)\end{array}$} & \multirow{2}{*}{$\begin{array}{c}\text { Univariate } \\
\text { analysis } \\
\text { p value }\end{array}$} & \multicolumn{4}{|c|}{$\begin{array}{c}\text { Multivariate } \\
\text { analysis }\end{array}$} \\
\hline & & & & $p$ value & $B$ & SE & $\operatorname{Exp}(B)$ \\
\hline Age (range) & $26.5(4-234)$ & $26(1-126)$ & $0.427 \S$ & $0.952^{\prime \prime}$ & 0.001 & 0.014 & 1.001 \\
\hline $\operatorname{Sex}(M: F)$ & $13: 7$ & $18: 11$ & $0.834^{*}$ & & & & \\
\hline Gestational age (range) & $34^{+6}\left(28^{+3}-42^{+1}\right)$ & $36^{+5}\left(28^{+5}-42^{+3}\right)$ & $0.063 \S$ & & & & \\
\hline Birth weight & $2.13 \pm 0.88$ & $2.67 \pm 0.74$ & $0.024 \div \pi$ & $0.254^{\prime \prime}$ & 0.565 & 0.496 & 1.760 \\
\hline Body weight & $2.50 \pm 0.68$ & $2.98 \pm 0.55$ & $0.008 \neq \pi$ & & & & \\
\hline \multicolumn{8}{|l|}{ Underlying disorder } \\
\hline Craniofacial anomaly & 7 & 3 & $0.068^{\dagger}$ & & & & \\
\hline Pulmonary problem & 8 & 6 & $0.141^{*}$ & & & & \\
\hline Cardiovascular problem & 6 & 8 & $0.854^{*}$ & & & & \\
\hline Neurologic problem & 3 & 8 & $0.488^{\dagger}$ & & & & \\
\hline TEF & 1 & 4 & $0.636^{+}$ & & & & \\
\hline Others & 3 & 8 & $0.488^{\dagger}$ & & & & \\
\hline Multiple & 3 & 10 & $0.191^{\dagger}$ & & & & \\
\hline Intubation history & $16(80.0 \%)$ & $7(24.1 \%)$ & $<0.001^{* \pi}$ & $0.002^{11 \pi}$ & 0.202 & 1.641 & 1.224 \\
\hline Duration of intubation (range) & $25.5(1-73)$ & $30(4-121)$ & $0.763 \S$ & & & & \\
\hline
\end{tabular}

Body weight was not included in the multivariate analysis due to close correlation between birth weight and body weight. $*$ Pearson chi-squared test, tFischer's exact test, ‡Student t-test, \$Mann Whitney U test, "binary logistic regression analysis, "Istatistical significance $(p<0.05)$. B: standardized coefficient, Exp (B): odds ratio, SE: standard error, TEF: tracheoesophageal fistula

tively and safely managed by orotracheal intubation, seldom needing tracheostomy. In previous pediatric studies, reported tracheostomy rates have ranged from $0.55-2.7 \% .{ }^{8,9)}$ Our retrospective analysis similarly yielded a tracheostomy rate of $2.03 \%$ (38/1548) for all admissions to NICU during the study period. However, airway examinations in neonates are not routinely done, and because tracheostomies in neonates are so rare, few standardized protocols have been developed. ${ }^{10)}$ The airway characteristics in newborns may explain this phenomenon. ${ }^{11)}$ Neonates seem better protected than adults and older children from intubation injury, ${ }^{12)}$ given their inherent airway plasticity and the pliable nature of deployed endotracheal tubes. They are thus capable of sustained (or indefinite) endotracheal intubation, without great risk of damage to larynx or subglottis. $^{13)}$

Still, few studies examining duration of intubation and conversion to tracheostomy in NICU patients have been published. Sidman, et al. ${ }^{9}$ ) suggested that infants needing $>4-6$ months of mechanical ventilation, whatever the cause, might be candidates for tracheostomy tubes, in lieu of continued endotracheal intubation. In another study, mobility, swallowing/feeding, vocalization, expedited hospital discharge, and parental bonding all seemed to improve after tracheostomy tube placement (vs. extended endotracheal intubation) and was urged in children whose neurologic or pulmonary disease precluded early extubation. ${ }^{14)}$ On the other hand, Gomes Silva, et al. ${ }^{15)}$ performed a meta-analysis of currently available studies, comparing early and late tracheostomy placement. They concluded that supporting evidence linked to timing of tracheostomy was not strong.

As already mentioned, about half of all airway examinations originating from NICU in this study culminated in tracheostomy. This is a much higher rate than that recorded in neonate populations at large, underscoring the critical role of pediatricians. Any suspected upper airway problem warrants an otolaryngologist's input for proper assessment. Furthermore, our analysis showed that the only significant correlate of tracheostomy was whether or not a patient had been previously intubated. Therefore, close observation of extubated patients is advised, regardless of duration of intubation, consulting an otolaryngologist promptly if signs of upper airway obstruction develop. Finally, careful monitoring of patients with low birth weights is needed after extubations. ${ }^{16)}$

Despite the advantages of tracheostomies, parents of neonates and their family members experience a diminished quality of life under these circumstances. Findings in comparable studies were aligned with ours, reporting decannulation rates of $60-70 \%$ and $30-40 \%$ rates of open surgical procedures (e.g., laryngotracheal resection). ${ }^{17,18)}$ Families of NICU patients should be educated on outcomes of tracheostomies; and the required multidisciplinary team, including otolaryngologists, pulmonologists, cardiologists, neurologists, primary care phy- 
sicians, nurses, therapists, and equipment specialists, must be well-informed and skilled in the management of tracheostomy tubes.

In conclusion, upper airway problems in NICU patients accompany a variety of disorders. Accurate diagnosis and appropriate treatment are enabled by thorough bedside and intraoperative assessments. As our findings indicate, patients with histories of intubation are at increased risk of tracheostomy; and although no protocols for routine neonatal airway examinations currently exist, pediatricians must be vigilant in susceptible patients, maintaining suitable communication with otolaryngologic colleagues.

\section{REFERENCES}

1) Walner DL, Loewen MS, Kimura RE. Neonatal subglottic stenosis-incidence and trends. Laryngoscope 2001;111(1):48-51.

2) Overman AE, Liu M, Kurachek SC, Shreve MR, Maynard RC, Mammel MC, et al. Tracheostomy for infants requiring prolonged mechanical ventilation: 10 years' experience. Pediatrics 2013;131(5): e1491-6.

3) L'Her E, Brochard L. Tracheostomy in the ICU: why, when and how? In: Mancebo J, Net A, Brochard L, editors. Mechanical ventilation and weaning. Berlin: Springer Berlin Heidelberg;2002. p.360-74.

4) Kremer B, Botos-Kremer AI, Eckel HE, Schlöndorff G. Indications, complications, and surgical techniques for pediatric tracheostomies-an update. J Pediatr Surg 2002;37(11):1556-62.

5) Al-Samri M, Mitchell I, Drummond DS, Bjornson C. Tracheostomy in children: a population-based experience over 17 years. Pediatr Pulmonol 2010;45(5):487-93.

6) Berry JG, Graham RJ, Roberson DW, Rhein L, Graham DA, Zhou J, et al. Patient characteristics associated with in-hospital mortality in children following tracheotomy. Arch Dis Child 2010;95(9):703-10.

7) Wetmore RF, Handler SD, Potsic WP. Pediatric tracheostomy. Experience during the past decade. Ann Otol Rhinol Laryngol 1982;91(6 Pt 1):628-32.

8) Freeland AP, Wright JL, Ardran GM. Developmental influences of infant tracheostomy. J Laryngol Otol 1974;88(10):927-36.

9) Sidman JD, Jaguan A, Couser RJ. Tracheotomy and decannulation rates in a level 3 neonatal intensive care unit: a 12-year study. Laryngoscope 2006;116(1):136-9.

10) Pereira KD, MacGregor AR, McDuffie CM, Mitchell RB. Tracheostomy in preterm infants: current trends. Arch Otolaryngol Head Neck Surg 2003;129(12):1268-71.

11) Grundfast KM, Camilon FS Jr, Pransky S, Barber CS, Fink R. Prospective study of subglottic stenosis in intubated neonates. Ann Otol Rhinol Laryngol 1990;99(5 Pt 1):390-5.

12) Freeman GR. A comparative analysis of endotracheal intubation in neonates, children and adults: complications, prevention and treatment. Laryngoscope 1972;82(8):1385-98.

13) Dankle SK, Schuller DE, McClead RE. Risk factors for neonatal acquired subglottic stenosis. Ann Otol Rhinol Laryngol 1986;95(6 Pt 1):626-30.

14) Pransky SM. Evaluation of the compromised neonatal airway. Pediatr Clin North Am 1989;36(6):1571-82.

15) Gomes Silva BN, Andriolo RB, Saconato H, Atallah AN, Valente O. Early versus late tracheostomy for critically ill patients. Cochrane Database Syst Rev 2012;(3):CD007271

16) Viswanathan S, Mathew A, Worth A, Mhanna MJ. Risk factors associated with the need for a tracheostomy in extremely low birth weight infants. Pediatr Pulmonol 2013;48(2):146-50.

17) Baud O. Postnatal steroid treatment and brain development. Arch Dis Child Fetal Neonatal Ed 2004;89(2):F96-100.

18) Rane S, Bathula S, Thomas RL, Natarajan G. Outcomes of tracheostomy in the neonatal intensive care unit: is there an optimal time? J Matern Fetal Neonatal Med 2014;27(12):1257-61. 